\title{
A interiorização da covid-19 na Amazônia: reflexões sobre o passado e o presente da saúde pública*
}

\author{
The interiorization of covid-19 in the Amazon region: \\ reflections on the past and present of public health
}

\section{Érico Silva Munizi \\ ' Professor, Faculdade de História/ Universidade Federal do Pará. \\ Bragança - PA - Brasil \\ orcid.org/0000-0002-5543-4266 \\ ericosilvamuniz@gmail.com}

Recebido em 3 ago. 2020.

Aprovado em 30 set. 2020.
MUNIZ, Érico Silva. A interiorização da covid-19 na Amazônia: reflexões sobre o passado e o presente da saúde pública. História, Ciências, Saúde Manguinhos, Rio de Janeiro, v.28, n.3, jul.-set. 2021, p.875-878.

\section{Resumo}

A partir de contribuições teóricas do campo da história das ciências, o presente texto debate aspectos das etapas das pandemias entendidas como fenômeno social e como tem ocorrido o processo de interiorização da covid-19 na Amazônia. A chegada da doença aos vastos territórios da floresta tem deixado mais evidente o processo de acesso diferenciado à saúde pública, com concentração de serviços e profissionais nas maiores cidades da região Norte. O crescimento dos índices do coronavírus na floresta evidencia, portanto, as desigualdades sociais históricas da região e os problemas no acesso à cidadania na sociedade brasileira.

Palavras-chave: interiorização; covid-19; Amazônia, coronavírus.

\section{Abstract}

This text uses theoretical contributions from the history of science to discuss aspects of the stages of pandemics understood as social phenomena and how covid-19 moved into the interior of the Amazon region. The arrival of this disease in the vast forest territory made differentiated access to public health more evident, with services and professionals concentrated in the larger cities in the north of Brazil. The rise in coronavirus rates within the forest consequently highlights the history of social inequalities in the region and problems accessing citizenship in Brazilian society.

Keywords: interiorization; covid-19; Amazon region, coronavirus. 
$\mathrm{D}$ esde o mês de abril de 2020, a pandemia de covid-19 tem encontrado terreno fértil na região amazônica. Além das grandes cidades da região, os interiores da floresta vivenciaram o rápido aumento no número de casos, contexto em que as desigualdades sociais e de acesso a serviços de saúde ficam ainda mais evidenciadas. No entanto, a preocupação de estabelecer barreiras para controle da contaminação e a necessidade de estruturar serviços de saúde não constituem novidade. Parte das medidas que são implementadas atualmente foram paliativos históricos da estruturação da saúde pública.

Quarentena, medidas de isolamento, vigilância de portos e aeroportos, e cordões sanitários isolando cidades e nações são decisões comuns neste período em que o mundo tem vivenciado a pandemia do novo coronavírus. Essas ações, na realidade, são antigas conhecidas do campo da saúde pública. Algumas delas foram as primeiras maneiras que os Estados nacionais criaram para controlar a proliferação de doenças com a finalidade de salvar vidas.

Autores clássicos como Foucault (1979) e Rosen (1980) demonstraram que as origens da saúde pública contemporânea datam do século XVIII e remontam justamente ao controle de portos e circulação de epidemias, momento em que o viés coercitivo merecia destaque nas estruturas das polícias médicas. O campo de estudos da história da saúde e das doenças tem demonstrado que o fenômeno da doença é ao mesmo tempo biológico e social. Ou seja, só conseguimos apreender as dimensões do processo de adoecimento se, além da dimensão biomédica, buscarmos entender também seus impactos econômicos, as interdependências entre os grupos e os medos sociogênicos que são gerados. Em casos de epidemias e pandemias, essa assertiva é especialmente verdadeira, pois o impacto diante do desconhecido suspende a condição de normalidade, impondo novas dinâmicas para os formuladores de políticas públicas e para a opinião pública.

As doenças passam, portanto, por diversos enquadramentos sociais que variam ao longo da história. Charles Rosenberg (1992) sugere que as epidemias têm um padrão de comportamento que pode ser caracterizado em quatro momentos.

O primeiro é marcado pela aceitação gradual da dimensão do problema, etapa caracterizada pela tentativa de controlar o pânico e por desconfianças, momento em que prejuízos à economia são destacados.

Quando os números de doentes e óbitos já não permitem mais negar a realidade, a epidemia entra em uma segunda fase, que é a da aceitação do problema - nela ocorrem as buscas das raízes e possíveis saídas para o problema, momento marcado por explicações de cunho religioso e científico, variando conforme cada sociedade.

O terceiro ato do enquadramento histórico dos fenômenos epidêmicos implica as ações de saúde pública que são implementadas, fase em que se debatem as modalidades de isolamento e quarentenas, a interrupção de atividades econômicas e do comércio, quando a sociedade demanda do poder público ações efetivas. A pobreza e as desigualdades sociais ficam mais evidentes nesse período.

O quarto e último momento é quando os casos da doença começam a diminuir, até que desapareça como problema de saúde pública. É recorrente que se discutam, na última fase, os impactos e o legado pós-epidemia, juntamente com novas políticas e parâmetros de saúde para lidar com o problema (Rosenberg, 1992). 
No caso do coronavírus, a pandemia do século XXI, diversos têm sido os aspectos destacados pelos estudiosos, da filosofia à comunicação, da medicina à geografia. Os limites do capitalismo, a necessidade de ação do Estado nacional e a vulnerabilidade trazida pela globalização são alguns dos elementos que vêm à baila para contextualizar o novo momento.

De volta à realidade amazônica, podemos pensar no curso que o vírus vem fazendo pelos rios da floresta. No final de maio de 2020, a covid-19 registrava mais casos nos interiores do Amazonas e do Pará do que nas regiões metropolitanas de Manaus e Belém. No Amazonas, todos os leitos de unidade de terapia intensiva (UTI) estão localizados na capital, o que faz com que, em algumas localidades, viagens de centenas de quilômetros em navios ou UTIs aéreas sejam necessárias para atendimento médico adequado (Ações..., 14 maio 2020).

$\mathrm{O}$ arquipélago do Marajó, por sua vez, apresentava no fim do mês de maio índices de letalidade altíssimos, tendo o município de Breves uma das maiores taxas de mortalidade por covid-19 em todo o país naquele momento (Breves..., 14 maio 2020). Aliás, é no Marajó que se registram alguns dos menores índices de desenvolvimento humano (IDH) do Brasil. O Amapá sentiu especialmente os efeitos da crise: além do número insuficiente de vagas em hospitais, o estado ainda tem dificuldades para atrair mão de obra médica nas chamadas emergenciais para contratação de pessoal (Sem médicos..., 11 maio 2020).

Entre os povos indígenas, a pandemia adquire feições ainda mais graves. As doenças que ao longo de séculos entram pelos rios gerando surtos epidêmicos e vitimizando os povos originários enfatizam a vulnerabilidade imunológica desses grupos. Lideranças indígenas denunciam que a doença escancara os problemas existentes, agravados no momento de enfraquecimento da política indigenista, marcada por estruturas e distritos de saúde insuficientes para salvar vidas (Covid-19..., 17 jun. 2020).

Aliás, é necessário dizer que a história da interiorização da própria presença do Estado nacional brasileiro na Amazônia se deve em grande parte aos serviços de saúde pública e sua íntima relação com o combate às chamadas endemias rurais - como malária, leishmaniose, doença de Chagas, brucelose, febre amarela, esquistossomose, ancilostomose e bócio endêmico - que motivaram gerações de cientistas e sanitaristas no controle de doenças na região. É impossível resistir à comparação histórica com a gripe espanhola, considerando que a pandemia de 1918 também foi causada por um vírus respiratório e atingiu de maneira peculiar a Amazônia. Em trabalho recente, Abreu Júnior (2018) mostrou que a espanhola grassou em Belém e na região, que vivenciavam um frágil estado sanitário após o ciclo da borracha. O autor demonstra que a introdução da doença por rios e mares, o número reduzido de médicos e os registros de mortes acentuados nas periferias marcaram aquele momento do mundo pós-Primeira Guerra Mundial. Além disso, as estratégias de postos de socorro e os hospitais de isolamento para as vítimas da doença, que até então tinha causa desconhecida, guardam muitas semelhanças com o tempo presente.

Por fim, é possível afirmar, por meio de levantamentos de notícias e dados de secretarias estaduais e municipais de Saúde, que as faces das desigualdades sociais em tempos de covid-19 parecem ficar especialmente enfatizadas na região amazônica. As diferenças sociais que são estruturantes do capitalismo, entre elas o acesso diferenciado à saúde, marcam a contemporaneidade e mostram suas faces de maneira mais aguda em tempos de pandemia (Butler, 2020). A Amazônia, onde o rio é rua, marcada por forte presença 
de povos tradicionais, indígenas, quilombolas e ribeirinhos, vê no contexto da pandemia atual que as assimetrias nos modos de viver, adoecer e morrer na região sublinham as discrepâncias históricas da cidadania no Brasil.

\section{NOTA}

* O presente texto é uma versão mais completa, atualizada e submetida a revisão por pares de uma postagem veiculada no blog de História, Ciências, Saúde - Manguinhos.

\section{REFERÊNCIAS}

ABREU JÚNIOR, José Maria de Castro. O vírus e a cidade: rastros da gripe espanhola no cotidiano da cidade de Belém (1918). Belém: Paka-Tatu, 2018.

AÇÕES e discurso de ministro da Saúde mostram desconexão com avanço da pandemia no país. HuffPost Brasil, 14 maio 2020.

Disponível em: https://www.huffpostbrasil. com/entry/acoes-teich-coronavirus

br_5ebc67edc5b6dfbab782114c. Acesso em: 18 maio 2020 .

BREVES, no Pará, é a cidade com maior disparada no número de mortes por covid-19 no Brasil. G1 Pará, 14 maio 2020. Disponível em: https://g1.globo.com/pa/para/ noticia/2020/05/14/breves-no-para-e-a-cidadecom-maior-disparada-no-numero-de-mortespor-covid-19-no-brasil.ghtml. Acesso em: 18 maio 2020.

BUTLER, Judith. El capitalismo tiene sus limites. Sopa de Wuhan. [S.1.]: Editorial Aislamiento Social Preventivo y Obligatorio, 2020. p.5965. Disponível em: http://iips.usac.edu.gt/ wp-content/uploads/2020/03/Sopa-de-WuhanASPO.pdf. Acesso em: 21 maio 2020.
COVID-19 se espalha entre indígenas brasileiros e já ameaça povos isolados. El País Brasil, 17 jun. 2020. Disponível em: https://brasil.elpais. com/brasil/2020-06-17/covid-19-se-espalhaentre-indigenas-brasileiros-e-ja-ameaca-povosisolados.html. Acesso em: 20 jun. 2020.

FOUCAULT, Michel. Microfísica do poder. Rio de Janeiro: Graal, 1979.

ROSEN, George. Da polícia médica à medicina social: ensaios sobre a história da assistência médica. Rio de Janeiro: Graal, 1980.

ROSENBERG, Charles E. Explaining epidemics and other studies in the history of medicine. New York: Cambridge University Press, 1992.

SEM MÉDICOS, Amapá quer contratar cubanos; CRM se diz "totalmente contra". Uol, 11 maio 2020. Disponível em: https://noticias.uol.com. br/saude/ultimas-noticias/redacao/2020/05/11/ sem-medicos-ap-quer-chamar-cubanos-crm-sediz-totalmente-contra.htm. Acesso em: 20 maio 2020.

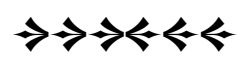

